\title{
Incidence and Risk Factors of Anti-tuberculosis Drugs Induced Hepatotoxicity in HIV/AIDS Patients Attending the Limbe and Buea Regional Hospitals
}

\author{
Jules CN Assob ${ }^{1 *}$, Peter F Nde ${ }^{2}$, Dickson S Nsagha ${ }^{2}$, Anna L Njunda ${ }^{3}$, Neville M Ngum ${ }^{3}$ and Marcelin N Ngowe ${ }^{4}$ \\ ${ }^{1}$ Department of Biomedical Sciences, Faculty of Health Sciences, University of Buea, Buea, SW Region, Cameroon \\ ${ }^{2}$ Department of Public Health and Hygiene, Faculty of Health Sciences, University of Buea, Buea, SW Region, Cameroon \\ ${ }^{3}$ Department of Medical Laboratory Sciences, Faculty of Health Sciences, University of Buea, Buea, SW Region, Cameroon \\ ${ }^{4}$ Department of Surgery Obstetrics and Gynaecology, Faculty of Health Sciences, University of Buea, Buea, SW Region, Cameroon
}

\begin{abstract}
Background: Hepatotoxicity is one of the most frequent adverse events induced by anti-tuberculosis chemotherapy and remains one of the main causes of treatment interruption during TB treatment leading to hospitalization and life threatening events. Despite the high prevalence of TB/HIV co-infection in sub-Sahara Africa, paucity of data still exists on anti-TB drugs induced hepatotoxicity in HIV patients. Therefore, this study was aimed to determine the incidence and risk factors of hepatotoxicity induced by anti-tuberculosis drugs in HIV patients.
\end{abstract}

Methods: From March to September 2013, we conducted a nested case-control study by retrospectively following up TB/HIV co-infected patients on anti-TB treatment at the Buea and Limbe Regional Hospitals. Patients who developed hepatotoxicity due to increased liver enzymes (ALAT and ASAT) after anti-TB treatment initiation were labelled as "cases" while those without hepatotoxicity were "controls". Each case was compared with 3 randomly selected controls.

Results: From the 191 TB/HIV patients recruited in the study, 26 developed hepatotoxicity. These 26 were labelled as cases and were compared to 78 randomly selected controls. WHO HIV/AIDS clinical stage $4, \mathrm{BMI}<18.5 \mathrm{Kg} / \mathrm{m}^{2}$, CD4 count $<50$ cells $/ \mathrm{mm} 3$, hepatitis B co-infection, and extra pulmonary TB were significantly associated with the development of anti-TB drug induced hepatotoxicity. These variables were then analysed using multivariate logistic regression and $B M l<18.5 \mathrm{Kg} / \mathrm{m} 2[P=0.033 ; A O R=3.7]$ and hepatitis $B$ co-infection $[P=0.019 ; A O R=6.6]$ were identified as independent predictors of anti-TB induced hepatotoxicity.

Conclusion: The incidence of anti-TB drug induced hepatotoxicity was $13.61 \%$. The findings suggest that TB/ HIV co-infected patients presenting with poor nutritional status as defined by $B M L 18.5 \mathrm{Kg} / \mathrm{m}^{2}$ andhepatitis $B$ should be closely monitored by clinicians especially during the intensive phase of anti-tuberculosis chemotherapy for better patient management and for the prevention of morbidity and mortality.

Keywords: Hepatotoxicity; Tuberculosis/HIV co-infection; Extrapulmonary tuberculosis; Body mass index

\section{Introduction}

In many developing countries, the disease burden of tuberculosis (TB) has been increasing as many people contract TB secondary to compromised immunity, largely due to high rates of human immunodeficiency virus (HIV) infection and the corresponding development of AIDS [1]. The WHO estimates that about 1.1 million (13\%) of the 8.6 million people who developed TB worldwide were HIV positive with Africa accounting for about $75 \%$ of the estimated number of HIV positive incident TB cases [2]. In Cameroon, the incidence of TB including TB/HIV co-infection stands at 238 per 100,000 [3] and in Africa, TB is the leading cause of illness and death in people living with HIV [4].

The interaction between these two infections is bidirectional. People living with HIV are not only found to have increased risk of developing active TB disease but are also found to have higher rates of TB relapse and treatment failure especially when living in areas of high TB incidence [5]. On the other hand, at the time of TB diagnosis, most patients with co-infection have advanced HIV disease as defined by low $\mathrm{CD} 4+$ cell counts, high viral loads and are grouped under either WHO Stage 3 or 4 HIV/AIDS disease [6]. Thus many patients who commence antiretroviral (ARV) treatment in areas of high TB prevalence will do so while on anti-TB treatment and amongst patients established on ARV, many will need to be treated for TB during their lifetime.

The time of initiation of anti-TB or ARV treatment in TB/HIV co-infected patients is crucial and the latest WHO treatment policy guideline stipulates that ARVs should be provided to all TB/HIV coinfected patients, irrespective of their CD4+ cell count (and to all people living with HIV/AIDS with a CD4 cell count less than 350) [7]. However, the combined use ARVs in individuals undergoing treatment for TB may be complicated with issues related to high pills burden, pharmacokinetic, drug interactions, immune reconstitution syndrome, and overlapping adverse effects [8,9].

*Corresponding author: Jules CN Assob, Department of Biomedical Sciences, Faculty of Health Sciences, University of Buea P.O. Box 63, SW Region, Cameroon Tel: +237 99629452; E-mail: juleclement@yahoo.fr

Received January 10, 2014; Accepted February 25, 2014; Published March 05, 2014

Citation: Assob JCN, Nde PF, Nsagha DS, Njunda AL, Ngum NM, et al. (2014) Incidence and Risk Factors of Anti-tuberculosis Drugs Induced Hepatotoxicity in HIV AIDS Patients Attending the Limbe and Buea Regional Hospitals. J AIDS Clin Res 5 288. doi:10.4172/2155-6113.1000288

Copyright: ( 2014 Assob JCN, et al. This is an open-access article distributed under the terms of the Creative Commons Attribution License, which permits unrestricted use, distribution, and reproduction in any medium, provided the original author and source are credited. 
Citation: Assob JCN, Nde PF, Nsagha DS, Njunda AL, Ngum NM, et al. (2014) Incidence and Risk Factors of Anti-tuberculosis Drugs Induced Hepatotoxicity in HIVIAIDS Patients Attending the Limbe and Buea Regional Hospitals. J AIDS Clin Res 5: 288. doi:10.4172/21556113.1000288

Page 2 of 6

Hepatotoxicity remains one of the most frequent adverse effects of anti-TB treatment and anti-TB drug-induced hepatotoxicity (ATDIH), as it has been shown to lead to both treatment interruptions and ineffectiveness $[10,11]$ while causing substantial morbidity and mortality [12]. ATDIH has been associated with three of the first line anti-TB drugs; rifampicin, isoniazid, and pyrazinamide [13] and the risk of developing ATDIH is enhanced when these drugs are used in combination.

Data show that hepatotoxicity induced by anti-TB drugs occurs in $2-28 \%$ in HIV negative TB treated patients [12]. Though the risk factors for hepatotoxicity during TB treatment have been assessed in HIVnegative patients [14], these risk factors have rarely been evaluated in HIV-infected patients, and despite the high prevalence of TB/HIV coinfection especially in Africa, paucity of data still exists on ATDIH in HIV patients as liver function tests are not usually routine laboratory tests in these countries. Besides, limited studies have been conducted that showed the incidence of hepatotoxicity induced by anti-TB drug among TB/HIV co-infected patients in the study area. In this study, we investigate the incidence of and determine significant risk factors and predictors for ATDIH in patients co-infected with TB/HIV.

\section{Methods}

We conducted a nested case-control study involving prospectively enrolled TB/HIV co-infected inpatients and/or outpatients visiting the TB units of the Buea and Limbe regional Hospitals in Fako Division of the South West Region of Cameroon from March to September 2013. These hospitals are state-own hospitals that provide services to the approximately 40,000 inhabitants in Fako Division. The participants comprised both those who had and who had not started ARV treatment before commencing anti-TB treatment. All the participants were more than 18 years and satisfied a basic inclusion criterion of completely normal findings on alanine aminotransferase (ALAT) and aspartate aminotransferase (ASAT) at the beginning of tuberculosis treatment. Excluded from the study were participants with higher than normal ALAT and ASAT levels at the beginning of TB treatment. The participants who developed hepatotoxicity were labelled as "cases" and the remaining participants without hepatotoxicity were marked as "controls". Each case was compared with 3 randomly selected controls. Some variables were collected retrospectively from patients' registers while others were measured prospectively.

Blood samples were collected in five (5) phases; prior to commencement of TB treatment, three times during the intensive phases of TB treatment and one time during the continuation phase as follows:

- Phase 1: prior to placement on anti-TB treatment

- Phase 2: two weeks after initiation of anti-TB treatment

- Phase 3: one month after anti-TB treatment initiation

- Phase 4: two months after anti-TB treatment initiation

- Phase 5: three months after anti-TB treatment initiation

\section{Treatment protocol}

In Cameroon, the treatment of TB in HIV patients is the same as in HIV negative patients. According to her National Tuberculosis Manual for Health Personnel, a case definition of TB in HIV patients includes those new patients who have smear-positive pulmonary TB, those patients presenting with clinical signs and symptoms suggestive of pulmonary TB despite 3 negative sputum examinations and those with extra-pulmonary TB as defined by signs and symptoms of the organ affected. TB treatment according to this manual consists of an 8 weeks intensive phase combination of rifampicin, isoniazid, pyrazinamide and ethambutol (RHZE as 150/75/400/275 mg tablet) during the intensive phase followed by rifampicin and isoniazid (RH as $300 / 150$ $\mathrm{mg}$ ) for 4 months for all new cases. The treatment of TB relapse is an eight months therapy of two months RHZE and streptomycin (S), one month of RHZE and five months of RHE.

\section{Classification of hepatotoxicity}

Hepatotoxicity was defined solely on the basis of biochemical measurements as an elevation in serum ALAT and/or ASAT level from the normal range and was categorized according to a modified, standardized toxicity grade scale [15]. Normal serum ASAT and ALAT levels were considered as ASAT $=0-37$ and ALAT $<41$ IU/l Hepatotoxicity was classified as grade 1, 1.25-2.5xULN; grade 2, 2.6$5 x U L N$; grade 3, 5.1-10xULN; grade 4 , greater than 10xULN.

\section{Statistical analyses}

Statistical analyses were performed using Statistical Package for Social Sciences (SPSS) version 17.0. Frequencies and percentages were used to present categorical variables while means plus standard deviations or median and inter-quartile range were used to present continuous variables. The risk factors considered for the study were age group, gender, CD4+ cell count, hepatitis B co-infection, WHO clinical stage of HIV/AIDS, type of TB, body mass index (BMI), type of ARV regimen, and concurrent usage of cotrimozaxole with the dependent variable being the occurrence of ATDIH. The various risk factors in the study population were analysed using chi-square test for categorical variables or the independent t-test to compare means for continuous variables for the evaluation of the differences between the cases and controls. The variables were then evaluated with binary logistic regression to identify significant risk factors and compute odd ratios for the development of hepatotoxicity. Identified risk factors were imputed into multivariate regression model to identify independent predictors of hepatotoxicity induced by anti-TB drugs. $\mathrm{P}<0.05$ was considered as statistically significant. Kaplan Meier methods were used to estimate the probabilities of developing hepatotoxicity with duration of anti-TB drugs.

\section{Ethical considerations}

All aspects of the study were conducted in accordance to the Declaration of Helsinki (16) and conformed to international ethical standards. A favourable ethical approval was obtained from the South West Regional Delegation of Public Health and the Faculty of Health Sciences Ethical Review Board. Eligible males and females who fitted the selection criteria were free to participate in the study after been correctly schooled on the benefits and risks of the study and their signed informed concerns obtained.

\section{Results}

A total of $212 \mathrm{HIV} / \mathrm{TB}$ co-infected patients visiting the Limbe and Buea Regional hospitals in Fako Division of the South West region of Cameroon were eligible for the study. Seventeen (I7) of the eligible patients declined enrolment, one of the patients died during the early stages and 3 were lost during the early stages. A cohort of 191 patients participated in the study amongst whom, 26 developed grade 1 and above ATDIH, giving an incidence of $13.61 \%$. Each case was compare with three controls giving 78 . The characteristics of the 26 cases and 78 controls randomly selected controls are described in Table 1. 
Citation: Assob JCN, Nde PF, Nsagha DS, Njunda AL, Ngum NM, et al. (2014) Incidence and Risk Factors of Anti-tuberculosis Drugs Induced Hepatotoxicity in HIVIAIDS Patients Attending the Limbe and Buea Regional Hospitals. J AIDS Clin Res 5: 288. doi:10.4172/21556113.1000288

Page 3 of 6

The majority (62.5\%) were females. The median age of the cases was 40.5 years with an inter quartile range (IQR) of 34.75 to 48.25 while the median age of the controls was 39 years with an IQR of 33-45 years. The participants were stratified into three age categories; $15-30$ years, $31-45$ years and $>45$ years and the majority 12 cases $(46.15 \%)$ and 45 controls (45.57\%) were in the age range of $31-45$ years.

Sixty five $(62.46 \%)$ had sputum positive pulmonary tuberculosis (SPPTB), 12 (11.54\%) had sputum negative pulmonary tuberculosis (SNPTB), and the remaining $27(25.96 \%)$ had extra pulmonary tuberculosis. The body mass index (BMI) was stratified into two categories; $<18.5 \mathrm{~kg} / \mathrm{m}^{2}$ and $\geq 18.5 \mathrm{~kg} / \mathrm{m} 2$. Of the total study participants, $61(78.21 \%)$ had BMIs less than $18.5 \mathrm{~kg} / \mathrm{m} 2$. According to WHO HIV/ AIDS staging based on clinical co-infections or diseases, 77 (74.04\%) were on stage 3 and the remaining 27 (25.96\%) were in stage 4 . Seven (26.9\%) of the cases were positive for hepatitis B virus (HBV) while 5 (6.41\%) of the controls had HBV. The median (IQR) CD4+ cell counts were $47.5(37.5-115)$ cells $/ \mathrm{mm} 3$ for the cases and 99.5 (48.5-198.75) cells $/ \mathrm{mm} 3$ for the controls.

Only eleven (14.10\%) of the total participants were on the 8 months TB retreatment scheme (2HRZES/1HRZE/5HRE) therapy of which 2 were from the cases $(7.69 \%, n=26)$. Sixty-nine (19 cases and 50 controls) had been on ARV therapy with different ARV regimens before initiation of TB treatment of which 40 (57.97\%) were on nevirapinebased therapy, 25 (36.23\%) were on efavirenz-based therapy and the remaining $4(5.80 \%)$ were on boosted PIs. The mean number of days on ARV before commencement of anti-TB treatment was $97.26 \pm 82.41$

\begin{tabular}{|c|c|c|c|}
\hline \multicolumn{2}{|c|}{ Variables } & $\begin{array}{l}\text { Cases } \\
(\mathrm{N}=26)\end{array}$ & $\begin{array}{c}\text { Controls } \\
(\mathrm{N}=78)\end{array}$ \\
\hline \multirow{2}{*}{ Gender } & Male & $10(38 \%)$ & 29 (37.18\%) \\
\hline & Female & $16(62 \%)$ & 49 (62.82\%) \\
\hline \multirow{4}{*}{ Age } & Mean ( \pm SD) & $42.04(11.86)$ & $40.42(9.96)$ \\
\hline & $15-30$ & $6(23 \%)$ & $10(13 \%)$ \\
\hline & $31-45$ & $12(46 \%)$ & $45(58 \%)$ \\
\hline & $>46$ & $8(31 \%)$ & $23(30 \%)$ \\
\hline \multirow{2}{*}{ Body Mass Index } & $<18.5$ & $20(77 \%)$ & $41(53 \%)$ \\
\hline & $\geq 18.5$ & $6(23 \%)$ & $37(47 \%)$ \\
\hline \multirow{3}{*}{ Type of TB } & SPPTB & $10(38 \%)$ & $55(70 \%)$ \\
\hline & SNPTB & $3(12 \%)$ & $9(12 \%)$ \\
\hline & EPTB & $13(50 \%)$ & $14(18 \%)$ \\
\hline \multirow{4}{*}{ CD4 + cell count } & $<50$ & $15(58 \%)$ & $22(29 \%)$ \\
\hline & $51-100$ & $4(15 \%)$ & $18(23 \%)$ \\
\hline & $100-200$ & $6(23 \%)$ & $19(24 \%))$ \\
\hline & $>200$ & $1(4 \%)$ & $19(24 \%)$ \\
\hline \multirow{2}{*}{ Hepatitis B co-infection } & Yes & $7(27 \%)$ & $4(5 \%)$ \\
\hline & No & 19 (73\%) & $74(95 \%)$ \\
\hline \multirow{2}{*}{ WHO HIVIAIDS stage } & Stage 3 & $13(50 \%)$ & $64(82 \%)$ \\
\hline & Stage 4 & $13(50 \%)$ & $14(18 \%)$ \\
\hline \multirow{2}{*}{$\begin{array}{c}\text { ARV before TB } \\
\text { treatment }\end{array}$} & Yes & $19(73 \%)$ & $50(64 \%)$ \\
\hline & No & $7(27 \%)$ & $28(36 \%)$ \\
\hline \multirow{3}{*}{$A R V$ regimen } & EFV based & $7(37 \%)$ & $18(36 \%)$ \\
\hline & NVP based & $11(58 \%)$ & $29(58 \%)$ \\
\hline & Boosted Pls based & $1(5 \%)$ & $3(6 \%)$ \\
\hline \multirow{2}{*}{ Anti-TB Regimen } & 2HRZES/1HRZE/5HRE & $2(8 \%)$ & $9(11 \%)$ \\
\hline & 2HRZE/4HR & $24(92 \%)$ & $69(88 \%)$ \\
\hline \multirow{2}{*}{ Cotrimoxazole } & Yes & $18(69 \%)$ & $46(59 \%)$ \\
\hline & No & $8(31 \%)$ & $32(41 \%)$ \\
\hline
\end{tabular}

Table 1: Demographic and clinical characteristics of the total 104 HIV/TB coinfected patients.

\begin{tabular}{|c|c|c|}
\hline Variables & Measurements & No of cases (\%), N=26 \\
\hline ASAT & $1.25-2.5 \times$ ULN & $16(69 \%)$ \\
\hline & $2.6-5 \times$ ULN & $9(27 \%)$ \\
\hline & $5.1-10 \times$ ULN & $1(4 \%)$ \\
\hline & $10 \times$ ULN & $0(0 \%)$ \\
\hline & $1.25-2.5 \times$ ULN\# & $17(62 \%)$ \\
\hline & $2.6-5 \times$ ULN & $8(38 \%)$ \\
\hline & $5.1-10 \times$ ULN & $1(4 \%)$ \\
\hline Severity & $10 \times$ ULN & $0(0 \%)$ \\
\hline Grade 1 & Level of liver enzymes & No of Cases (N=26) \\
\hline Grade 2 & $1.25-2.5 \times$ ULN & $17(65 \%)$ \\
\hline Grade 3 & $2.6-5 \times$ ULN & $8(31 \%)$ \\
\hline Grade 4 & $5.1-10 \times$ ULN & $1(4 \%)$ \\
\hline & $10 \times$ ULN & $0(0 \%)$ \\
\hline
\end{tabular}

ULN: upper limit of normal, *Normal level $\leq 37 \mathrm{UI} / \mathrm{l}$, \#Normal level $\leq 41 \mathrm{UI} / \mathrm{l}$

Table 2: Classification of hepatotoxicity into grades $1-4$ among the 26 cases.

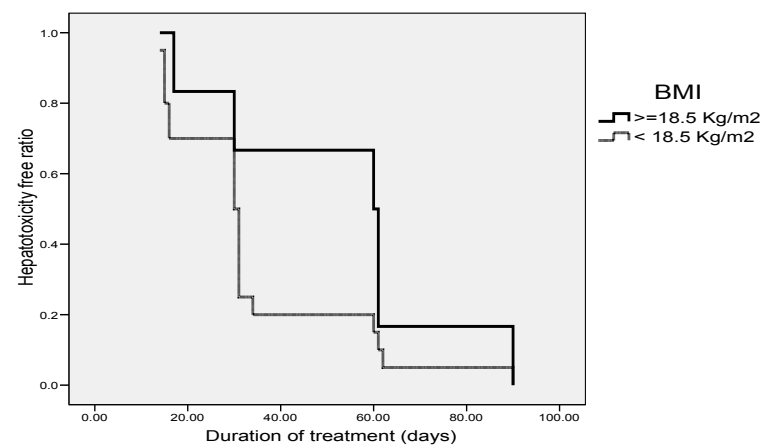

Figure 1: Variation in Time-To-Hepatotoxicity between cases with $\mathrm{BMI}<18.5$ $\mathrm{kg} / \mathrm{m}^{2}$ and $\mathrm{BMI} \geq 18.5 \mathrm{~kg} / \mathrm{m}^{2}$.

and $142.76 \pm 85.94$ for the cases and controls respectively. A total of $64(61.53 \%)$ were on cotrimoxazole prophylaxis of which $18(17.31 \%)$ were from the cases.

NVP: Nevirapine, EFV: Efavirenz, PIs: Protease Inhibitors, H: Isoniazid, R: Rifampicin, Z: Pyrazinamide, E: Ethambutol, S: Streptomycin, SPPTB: Sputum Positive Pulmonary Tuberculosis, SNPTB: Sputum Negative Pulmonary Tuberculosis, EPTB: Extra Pulmonary Tuberculosis

\section{Biochemical scope of ATDIH}

The increase in liver enzymes were classified into different grades of hepatotoxicity (Table 2) according to modified, standardized toxicity grade scale [15]. The timeline to the development of the various grades of ATDIH following initiation of anti-TB treatment has been presented Figure 1.

\section{Identification of factors associated with the development of ATDH}

Between the cases and the controls, no significant difference was observed with respect to gender $(\mathrm{P}=0.726)$. The mean ages were 39.84 $( \pm 11.28)$ for the cases and $40.50( \pm 10.05)$ for the controls $(\mathrm{P}=0.559)$ and the three age groups were not significantly different between the cases and the controls and no association was found between age groups and the occurrence of ATDH. The cases had a significantly higher number of participants with a CD $4+$ cells count $<50$ cells $/ \mathrm{mm} 3$ than the controls $(\mathrm{P}=0.018)$. 
Citation: Assob JCN, Nde PF, Nsagha DS, Njunda AL, Ngum NM, et al. (2014) Incidence and Risk Factors of Anti-tuberculosis Drugs Induced Hepatotoxicity in HIVIAIDS Patients Attending the Limbe and Buea Regional Hospitals. J AIDS Clin Res 5: 288. doi:10.4172/21556113.1000288

Page 4 of 6

Eleven out of the 104 participants were positive for HBV. The cases had a significant number of participants $(29.92 \%, \mathrm{~N}=26)$ who were coinfected with HBV than the controls $(5.13 \%, \mathrm{~N}=78), \mathrm{P}=0.005$. Cases were also more likely to be malnourished as defined by $\mathrm{BMI}<18.5 \mathrm{~kg} /$ $\mathrm{m}^{2}$ as compared to the controls; $20(76.92 \%, \mathrm{~N}=26)$ of the cases versus $41(52.56 \%, \mathrm{~N}=78)$ of the controls had $\mathrm{BMI}<18.5 \mathrm{~kg} / \mathrm{m}^{2}(\mathrm{P}=0.033)$. A majority of the cases, 13 (50\%) were in WHO clinical stage 4 of HIV/ AIDS compared to $14(17.95 \%)$ of the controls $(\mathrm{P}=0.001)$ and extrapulmonary TB was found to be more common in the cases $13(50 \%)$ versus $14(17.95 \%)$ in controls. Hence from bivariate analysis (Table 3), BMI $<18.5 \mathrm{~kg} / \mathrm{m} 2$, WHO clinical stage 4 of HIV/AIDS, hepatitis $B$ co-infection, $\mathrm{CD} 4+$ cells count $<50$ cells $/ \mathrm{mm} 3$, and extra pulmonary $\mathrm{TB}$ were significantly associated with the development of ATDIH.

In the multivariate logistic regression using the backwards elimination form of step-wise regression, we included the variables $\mathrm{BMI}<18.5 \mathrm{~kg} / \mathrm{m} 2$, WHO clinical stage $4, \mathrm{HBV}, \mathrm{CD} 4+$ cells count $<50$ cells $/ \mathrm{mm} 3$, and extra-pulmonary TB because they showed significance in the bivariate analyses at levels of $\mathrm{P}<0.05$. Results from this analysis showed that WHO clinical stage $4, \mathrm{CD} 4+$ cells count $<50$, and extrapulmonary TB were not predictors of ATDIH as they had P values $(\mathrm{P}>0.005)$ of $0.064,0.054$, and 0.064 respectively. However, the presence of HBV [P=0.019; AOR $(95 \% \mathrm{CI})=6.6(1.4-31.7)]$ and $\mathrm{BMI}<18.5 \mathrm{Kg} / \mathrm{m}^{2}$ $[\mathrm{P}=0.033$; $\mathrm{AOR}(95 \% \mathrm{CI})=3.7(1.1-12.1)]$ were shown to be independent predictors for the development of ATDIH in TB/HIV co-infected patients (Table 4 ).

A time-to-event analysis using Kaplan Meier analysis (Figure 1)

\begin{tabular}{|c|c|c|c|c|c|c|}
\hline \multicolumn{2}{|c|}{ Parameters } & \multirow{2}{*}{$\begin{array}{c}\begin{array}{c}\text { Cases } \\
(\mathbf{N}=\mathbf{2 6})\end{array} \\
10\end{array}$} & \multirow{2}{*}{\begin{tabular}{|c|}
$\begin{array}{c}\text { Controls } \\
(\mathbf{N}=\mathbf{7 8})\end{array}$ \\
29
\end{tabular}} & \multirow{2}{*}{\begin{tabular}{|c|} 
COR \\
1.0 \\
\end{tabular}} & \multirow[t]{2}{*}{$95 \% \mathrm{Cl}$} & \multirow[t]{2}{*}{ p value } \\
\hline & Male & & & & & \\
\hline Gender & Female & 16 & \begin{tabular}{|l|}
49 \\
\end{tabular} & 0.9 & $0.4-2.2$ & 0.726 \\
\hline \multirow{3}{*}{ Age } & $15-30$ & 6 & 8 & 1.0 & & \\
\hline & $31-45$ & 12 & 45 & 1.7 & $0.5-6.3$ & 0.409 \\
\hline & $>45$ & 8 & 23 & 0.8 & $0.3-2.1$ & 0.612 \\
\hline \multirow{2}{*}{ BMI } & $<18.5$ & 20 & 41 & 3.0 & $1.1-8.3$ & 0.033 \\
\hline & $\geq 18.5$ & 6 & 37 & 1.0 & & \\
\hline \multirow{4}{*}{$\begin{array}{l}\text { CD4+ cell } \\
\text { count }\end{array}$} & $<50$ & 15 & 22 & 13.0 & $(1.6-107.4)^{\#}$ & 0.018 \\
\hline & $51-100$ & 4 & 18 & 4.22 & $(0.4-41.5)$ & 0.216 \\
\hline & $101-200$ & 6 & 19 & 6.0 & $(0.7-54.8)$ & 0.112 \\
\hline & $>200$ & 1 & 19 & 1.0 & & \\
\hline \multirow{3}{*}{ Type of TB } & SPPTB & 10 & 55 & 1.0 & & \\
\hline & SNPTB & 3 & 9 & 1.8 & $0.4-7.9$ & 0.419 \\
\hline & EPTB & 13 & 14 & 5.1 & $1.8-14.0$ & 0.002 \\
\hline \multirow{2}{*}{$\begin{array}{l}\text { Hepatitis B } \\
\text { co-infection }\end{array}$} & No & 19 & 74 & 1.0 & & \\
\hline & Yes & 7 & 4 & 6.8 & $1.8-25.7$ & 0.005 \\
\hline \multirow{2}{*}{$\begin{array}{c}\text { ARV } \\
\text { treatment }\end{array}$} & No & 7 & 28 & 1.0 & & \\
\hline & Yes & 19 & 50 & 1.5 & $0.5-4.1$ & 0.403 \\
\hline \multirow{3}{*}{ ARV Regimen } & EFV-based & 7 & 18 & 1 & & \\
\hline & NVP based & 11 & 29 & 0.9 & $0.3-3.0$ & 0.965 \\
\hline & Boosted Pls & 1 & 3 & 0.9 & $0.76-9.70$ & 0.901 \\
\hline \multirow{2}{*}{$\begin{array}{l}\text { WHO HIVI } \\
\text { AIDS stage }\end{array}$} & Stage 3 & 13 & 64 & 1.0 & & \\
\hline & Stage 4 & 13 & 14 & 4.6 & $1.7-11.9$ & 0.002 \\
\hline \multirow{2}{*}{ Cotrimoxazole } & No & 8 & 32 & 1.0 & & \\
\hline & Yes & 18 & 46 & 1.6 & $0.6-4.0$ & 0.354 \\
\hline
\end{tabular}

Cl: Confidence interval, COR: Crude Odd Ratio, NVP: nevirapine, EFV: efavirenz, PIs: Protease inhibitors ${ }^{"} \mathrm{Cl}$ is so wide that it might not be considered useful in providing information about the value of $\mathrm{CD}^{+}$cells, although the OR is significant

Table 3: Bivariate analysis of risk factors for grade 1-4 anti-TB induced hepatotoxicity in TB/HIV co-infected patients.

\begin{tabular}{|c|c|c|c|c|c|c|c|}
\hline \multicolumn{2}{|c|}{ Parameters } & $\begin{array}{l}\text { Cases } \\
(\mathrm{N}=26)\end{array}$ & $\begin{array}{c}\text { Controls } \\
(\mathrm{N}=78)\end{array}$ & $\begin{array}{c}\text { COR } \\
(95 \% \mathrm{Cl})\end{array}$ & $\begin{array}{l}p \\
\text { value }\end{array}$ & $\begin{array}{l}\text { AOR } \\
(95 \% \mathrm{Cl})\end{array}$ & $\begin{array}{l}p \\
\text { value }\end{array}$ \\
\hline \multirow{2}{*}{ BMI } & $<18.5$ & 20 & 41 & $3.0(1.1-8.3)$ & 0.033 & $3.7(1.1-12.3)$ & 0.033 \\
\hline & $\geq 18.5$ & 6 & 37 & 1.0 & & & \\
\hline \multirow{4}{*}{$\begin{array}{c}\text { CD4+cell } \\
\text { count }\end{array}$} & $<50$ & 15 & 22 & $13.0(1.6-107.4)$ & 0.018 & $8.7(1.0-79.1)$ & 0.054 \\
\hline & $51-100$ & 4 & 18 & $4.2(0.4-41.5)$ & 0.216 & $3.3(0.3-38.1)$ & 0.332 \\
\hline & $\begin{array}{l}101- \\
200\end{array}$ & 6 & 19 & $6.0(0.7-54.8)$ & 0.112 & $4.1(0.4-46.6)$ & 0.200 \\
\hline & $>200$ & 1 & 19 & 1.0 & & & \\
\hline \multirow{3}{*}{$\begin{array}{c}\text { Type of } \\
\text { TB }\end{array}$} & SPPTB & 10 & 55 & 1.0 & & & \\
\hline & SNPTB & 3 & 9 & $1.8(0.4-7.9)$ & 0.419 & $1.8(0.3-9.8)$ & 0.496 \\
\hline & EPTB & 13 & 14 & $5.1(1.8-14.0)$ & 0.002 & $3.1(1.0-10.1)$ & 0.064 \\
\hline \multirow{2}{*}{$\begin{array}{l}\text { Hepatitis } \\
\text { B co- } \\
\text { infection }\end{array}$} & No & 19 & 74 & 1.0 & & & \\
\hline & Yes & 7 & 4 & $6.8(1.8-25.7)$ & 0.005 & $6.6(1.4-31.7)$ & 0.019 \\
\hline \multirow{2}{*}{$\begin{array}{l}\text { WHO } \\
\text { stage }\end{array}$} & Stage 3 & 13 & 64 & 1.0 & & & \\
\hline & Stage 4 & 13 & 14 & $2.8(1.1-6.9)$ & 0.027 & $3.1(0.9-10.1)$ & 0.064 \\
\hline
\end{tabular}

COR: Crude Odd Ratio, AOR: Adjusted Odd ratio, $\mathrm{Cl}$ : Confidence Interval

Table 4: Multivariate regression analysis of variables associated with anti-TB drug induced hepatotoxicity.

showed that HBV co-infected patients had lower mean days; 19.86 $( \pm 2.77)$ days to the development of anti-TB induced hepatotoxicity than those without hepatitis B $44.90( \pm 5.18)$ days $(\mathrm{P}=0.001)$. Mean time to onset of ATDIH were lower in participants with $\mathrm{BMI}<18.5 \mathrm{Kg} / \mathrm{m}^{2}$ compared to those with $\mathrm{BMI} \geq 18.5 \mathrm{Kg} / \mathrm{m} 2 ; 33.65( \pm 4.46)$, and 53.17 $( \pm 10.60)$ respectively $(\mathrm{p}=0.146)$.

\section{Discussion}

There is little evidence in the literature of the assessment of the rate of anti-TB induced hepatotoxicity in TB/HIV co-infected patients in Cameroon. In this study, the incidence of hepatotoxicity induced by anti-TB drugs in patients co-infected with TB/HIV was $13.61 \%$. A recent study in Ethiopia reported an incidence of $11.5 \%$ among TB/HIV co-infected patients $[16,17]$ which is in conformity with the current study. However a higher incidence (30.0\%) was reported by Yimer et al. [18]. The differences in incidences are probably due to differences in the investigators' definition of hepatotoxicity, ethnic susceptibility pertaining to drug metabolism, population characteristics, and most especially as the present study did not include the effect of ARV induced hepatotoxicity.

The present study identifies HBV co-infection and BMI $<18 \mathrm{~kg} /$ $\mathrm{m}^{2}$ as independent predictors for the development of anti-TB induced hepatotoxicity. The presence of hepatitis B co-infection appeared to increase the risk ATDIH in TB/HIV co-infected persons by 6.6 folds and the occurrence of ATDIH was significantly faster (19.86 \pm 2.77 days) in HBV co-infected patients than those without hepatitis B $(44.90 \pm 5.18$ days). Wong and colleagues reported that co-infection with HBV was a risk factor under both univariate analysis $(\mathrm{p}=0.011)$ and multiple logistic regression $(\mathrm{p}<0.001)$ for the development of ATDIH compared to non HBV patients on anti-TB drugs [19]. The mechanism of elevation of transaminases mediated by HBV might be related to underlying liver damage and HBV mediated acute hepatic inflammation or through complex immune reconstitution that alters the response against hepatitis $\mathrm{B}$ virus antigens after suppression of HIV replication by HAART [20] in TB/HIV patients co-infected with hepatitis B. Nevertheless, although some studies [21,22] have found no association between HBV and anti-TB hepatotoxicity, the authors of one of the studies reiterated that the absence of this association must be 
Citation: Assob JCN, Nde PF, Nsagha DS, Njunda AL, Ngum NM, et al. (2014) Incidence and Risk Factors of Anti-tuberculosis Drugs Induced Hepatotoxicity in HIVIAIDS Patients Attending the Limbe and Buea Regional Hospitals. J AIDS Clin Res 5: 288. doi:10.4172/21556113.1000288

Page 5 of 6

interpreted with caution as data for this variable were missing in their study, possibly because they were conducted with a small number of patients with the HBV [21].

Poor nutritional status as defined by $\mathrm{BMI}<18.5 \mathrm{Kg} / \mathrm{m}^{2}$ was found to be an independent predictor of hepatotoxicity induced by anti$\mathrm{TB}$ drugs after adjusting for other variables in multivariate logistic regression $(\mathrm{P}=0.033)$. This result is in agreement with results from different studies $[23,24]$. In the current study, the occurrence of ATDIH was insignificantly faster $(33.65 \pm 4.46$ days $)$ in patients with $\mathrm{BMI}<18.5$ $\mathrm{Kg} / \mathrm{m}^{2}$ than those with $\mathrm{BMI} \geq 18.5 \mathrm{Kg} / \mathrm{m}^{2}(53.17 \pm 10.60$ days $)$. The association between malnutrition and hepatotoxicity has been linked to the derangement and disruption of drug metabolism pathways during protein energy malnutrition [25] including the acetylation pathways involved in isoniazid metabolism and the depletion of glutathione stores, thus making patients more vulnerable to oxidative injuries, and slowing the rate at which the liver metabolizes drugs [26]. A decrease in protective mechanism during INH treatment has also been observed in protein energy malnourished rats [27].

Some studies have reported a relationship between diminished immune status, as represented by the low CD4+ cell count and the occurrence of hepatotoxicity which might be partly explained by polypharmacy due to the occurrence of a range of opportunistic infections $[27,28]$. In the current study, CD4+ cell count $<50$ cells/ $\mathrm{mm} 3$ was significantly associated with ATDIH but did not pass as an independent predictor on the multivariate model. Unlike this study, previous research did not find an association betweenthe involvement of opportunistic infections and the development of hepatotoxicity, and accredited the risk to probably an unknown immunological factor thought to be present in individuals with low CD4+ cells [21,29].

A disproportionately higher risk of developing hepatotoxicity was observed in patients with extra pulmonary $\mathrm{TB}$, suggesting that this group of patients may have some subclinical liver involvementswhich may predispose ATDH. Anand et al. [30] and Singla et al. [31] had similar findings; hence suggesting that usual monitoring of liver function tests may be necessary for patients with extra pulmonary TB.

The current study showed that WHO HIV/AIDS clinical stage 4 patients were at higher risk of developing ATDH. This could be explained by the usual presence of a range of disseminated opportunistic infections in this group of patients that might have direct subclinical liver involvementleading to cell death or might be due to a consumption of a large array of medications secondary to these opportunistic infections.

The present study did not find an association between age and the occurrence of ATDIH contrary to what was seen in India involving 346 patients undergoing tuberculosis treatment [23]. In that study, Sharma and colleagues reported age as an independent risk factor for the development of hepatotoxicity [23]. However, a substantial number of studies have demonstrated a lack of correlation between age and the development of anti-TB hepatotoxicity $[30,32]$ which is consistent with the present finding. Some studies have also reported old age as a risk factor for the development of anti-TB drug induced hepatotoxicity $[21,33]$. However the present study did not find any correlation between older age and ATDH.

With respect to gender, several studies have reported that females are at increased risk of hepatotoxicity compared with males [34,35] which might be attributable to variations in pharmacokinetics and metabolism patterns between both genders. In the current study, no significant association was observed between gender and hepatotoxicity, which is in corroboration with findings from Ethiopia [17] and India [23].

The median number of days to anti-TB hepatotoxicity after initiation of anti-TB drugs was 31 days (IQR 16.75-60.25) which is in consistence with results of other studies $[17,21]$. Seven of the cases developed hepatotoxicity by 15 days of anti-TB treatment and by the fourth week of anti-TB treatment, the number had risen to 18 (69.23\%). This is increment is in agreement with results from Senaratne and colleagues [36] who reported a greater majority (58\%) of their study participants developing hepatotoxicity during the first 4 weeks of anti-TB treatment. This could potentially affect the TB treatment leading to unsuccessful treatment outcomes and prolonged intensive phase treatment. A study in Tanzania [37] reported that none out of 112 patients developed hepatotoxicity during the first 2 months of anti-TB treatment differing with the present study. This difference might be accounted for by the differences in participants' characteristics; just $9.8 \%$ were co-infected with HIV, only $7.1 \%$ were co-infected with hepatitis and only $5.4 \%$ were on ARVs in that study with low impact on the liver for the first 2 months.

The concomitant use cotrimoxazole and anti-TB drugs had no effect on the development of hepatotoxicity. The use of concurrent ARV therapy with anti-TB drugs did not show any significant association with the outcome though it was considered a risk factor as a majority (66.35\%) of the total participants were on ARV therapy before commencing anti-TB treatments and as low level hepatotoxicity induced by HAART has been reported in this area [38]. This is in agreement with a study by Marks et al. in South Africa [39]. Similarly, Pukenyte et al. [21] did not find the concomitant use of ARVs and anti-TB drugs to be associated with liver toxicity although the concomitant use of both classes of drugs has been shown to exacerbate risk of drug induced liver damage [40]. In the present study, a majority $(11,57.90 \%)$ of the cases were on nevirapine based therapy as compared to 7 (36.84\%) who were on efavirenz based therapy. Studies $[41,42]$ have shown that patients on nevirapine based therapies are more susceptible to hepatotoxicity than those on efavirenz based therapy. Although this corroborates with the current study, the association of hepatotoxicity with nevirapine based therapy was not statistically significant.

In the current study, ATDIH has been investigated only during the first 3 months of anti-TB treatment ( 2 months of intensive phase plus 1 month of continuation phase) as most studies report hepatotoxic events occurring mostly during the intensive phase. Hence the present study might have missed late-onset hepatotoxicity commencing after 3 months of treatment. Another important limitation is that fact that the impacts of other hepatotoxic intakes such as alcohol or medications like acetaminophen, HMG-CoA reductase inhibitors, and herbs were not assessed. Lastly, therapy was not challenged to prove if the originality of the increased liver enzymes were truly due anti-TB drugs. Treatment regimens were neither halted nor changed to view if the increased liver enzymes could revert back to normal levels.

We conclude that among patients co-infected with TB/HIV, low grade hepatotoxicity induced by anti-TB drugs is not uncommon, and accounted for a substantial number of cases (13.61\%) with greater majority of hepatotoxic events occurring during the intensive phase of treatment. Low CD4+ cells count, HBV co-infection, extra pulmonary $\mathrm{TB}, \mathrm{BMI}<18 \mathrm{~kg} / \mathrm{m}^{2}$ and WHO HIV/AIDS stage 4 disease were identified as risk factors to the development of ATDIH with $\mathrm{BMI}<18 \mathrm{~kg} / \mathrm{m}^{2}$ and $\mathrm{HBV}$ passing as independent predictors. We therefore recommend that TB/HIV co-infected patients with lower BMI and HBV should be identified by clinicians so as to closely monitor their liver enzyme levels during the intensive phase of TB treatment for greater quality of 
Citation: Assob JCN, Nde PF, Nsagha DS, Njunda AL, Ngum NM, et al. (2014) Incidence and Risk Factors of Anti-tuberculosis Drugs Induced Hepatotoxicity in HIVIAIDS Patients Attending the Limbe and Buea Regional Hospitals. J AIDS Clin Res 5: 288. doi:10.4172/21556113.1000288

care. Since liver enzyme tests are not usually routine laboratory in subSahara Africa and where the financial burden of these tests lies upon the patient, we recommend a one-point cost-effective liver enzymes diagnosis at the third month of anti-TB treatment. This will facilitate the rapid diagnosis of any moderate to severe hepatotoxicity instead of the continuous diagnosis of mild hepatotoxicity during the intensive phase which might be due to hepatic adaptation.

\section{References}

1. Lawn SD, Zumla Al (2011) Tuberculosis. Lancet 378: 57-72.

2. World Health Organization (2012) Global Tuberculosis Report. WHO publisher Geneva: World Health Organisation 68-69.

3. World Health Organization (2013) Tuberculosis country profiles.

4. World Health Organization (2008) Global Tuberculosis Control: Surveillance, Planning, Financing: WHO Report. WHO, Geneva.

5. Lambert ML, Hasker E, Van Deun A, Roberfroid D, Boelaert M, et al. (2003) Recurrence in tuberculosis: relapse or reinfection? Lancet Infect Dis 3: 282-287.

6. Wolday D, Hailu B. Girma M, Hailu E, Sanders E, et al. (2003) Low CD4+ Tcell count and high HIV viral load precede the development of tuberculosis disease in a cohort of HIV-positive Ethiopians. Intl J Tubercul Lung Dis 7: 110-116.

7. World Health Organisation (2010) Antiretroviral therapy for HIV infection in adults and adolescents: Recommendations for a public health approach-2010 revision. WHO Press Geneva 20-22.

8. Lima MF, Melo HR (2012) Hepatotoxicity induced by antituberculosis drugs among patients coinfected with HIV and tuberculosis. Cad Saude Publica 28: 698-708.

9. Burman WJ (2005) Issues in the management of HIV related tuberculosis. Clin Chest Med 26: 283-294.

10. Lee WM (2003) Drug-Induced Hepatotoxicity. N Engl J Med 349: 474-485.

11. Walker U (2007) Antiretroviral therapy-induced liver alterations. Curr Opin HIV AIDS 2: 293-298.

12. Tostmann A, Boeree JM, Aarnoutse RE, Wiel CM, Andre JM, et al. (2008) Antituberculosis drug-induced hepatotoxicity: Concise up-to-date review. J Gastroenterol Hepatol 23: 192-202.

13. Girling DJ (1978) The hepatic toxicity of antituberculosis regimens containing isoniazid, rifampicin and pyrazinamide. Tubercle 59: 13-32.

14. Shakya R, Rao BS, Shrestha B (2004) Incidence of hepatotoxicity due to antitubercular medicines and assessment of risk factors. Ann Pharmacother 38: $1074-1079$

15. AIDS Clinical Trials Group (1996) Table of Grading Severity of Adult Adverse Experiences. Rockville, Md: Division of AIDS, National Institute of Allergy and Infectious Diseases.

16. The WMA Declaration of Helsinki - Ethical Principles for Medical Research Involving Human Subjects.

17. Hassen Ali A, Belachew T, Yami A, Ayen WY (2013) Anti-Tuberculosis Drug Induced Hepatotoxicity among TB/HIV Co-Infected Patients at Jimma University Hospital, Ethiopia: Nested Case-Control Study. PLoS ONE 8: e64622.

18. Yimer G, Ueda N, Habtewold A, Amogne W, Suda A, et al. (2011) Pharmacogenetic and pharmacokinetic biomarker for efavirenz based ARV and rifampicin based anti-TB drug induced liver injury in TB-HIV infected patients. PLoS ONE 6: e27810.

19. Wong WM, Wu PC, Yuen MF, Cheng CC, Yew WW, et al. (2000) Antituberculosis drug-related liver dysfunction in chronic hepatitis B infection. Hepatology 31 : 201-206

20. Nunez M, SorianoV (2005) Hepatotoxicity of antiretrovirals: incidence, mechanisms and management. Drug Saf 28: 53-66.

21. Pukenyte E, Lescure FX, Rey D, Rabaud C, Hoen B, et al. (2007) Incidence of and risk factors for severe liver toxicity in HIV-infected patients on antituberculosis treatment. Int J Tuberc Lung Dis 11: 78-84.

22. Wiroj M, Aroon L, Manosuthi W (2011) Hepatotoxicity in patients co-infected with tuberculosis and hiv-1 while receiving non-nucleoside reverse transcriptase inhibitor-based antiretroviral therapy and rifampicin-containing anti-tuberculosis regimen. Southeast Asian J Trop Med Public Health 42: 651-658.

23. Sharma SK, Balamurugan A, Saha PK, Pandey RM, Mehra NK (2002) Evaluation of clinical and immunogenetic risk factors for the development of hepatotoxicity during antituberculosis treatment. Am J Respir Crit Care Med 166: 916-919.

24. Singh J, Garg PK, Tandon RK (1996) Hepatotoxicity due to antituberculosis therapy. Clinical profile and reintroduction of therapy. J Clin Gastroenterol 22 211-214

25. Buchanan N, Eyberg C, Davis MD (1979) Isoniazid pharmacokinetics in kwashiorkor. S Afr Med J 56: 299-300.

26. Makhlouf HA, Helmy A, Fawzy E, El-Attar M, Rashed HA (2008) A prospective study of antituberculous drug-induced hepatotoxicity in an area endemic for liver diseases. Hepatol Int 2: 353-360.

27. Sodhi CP, Rana SV, Mehta SK, Vaiphei K, Attri S, et al. (1996) Study of oxidative stress in isoniazid-induced hepatic injury in young rats with and without proteinenergy malnutrition. J Biochem Toxicol 11: 139-146

28. Yimer G, Aderaye G, Amogne W, Makonnen E, Aklillu E, et al. (2008) Antituberculosis therapy-induced hepatotoxicity among Ethiopian HIV-positive and negative patients. PLoS One 3: e1809.

29. Pol S, Lebray P, Vallet-Pichard A (2004) HIV infection and hepatic enzyme abnormalities: intricacies of the pathogenic mechanisms. Clin Infect Dis 38 : S65-72..

30. Anand AC, Seth AK, Paul M (2006) Risk factors of hepatotoxicity during antituberculosis treatment. MJAFI 62: 45-49.

31. Singla R, Sharma SK, Mohan A, Makharia G, Sreenivas V, et al. (2010) Evaluation of risk factors for antituberculosis treatment induced hepatotoxicity Indian J Med Res 132: 81-86.

32. Javadi MR, Shalviri G, Gholami K, Salamzadeh J, Maghooli G, et al. (2007) Adverse reactions of anti-tuberculosis drugs in hospitalized patients: incidence, severity and risk factors. Pharmacoepidemiol Drug Saf 16: 1104-1110.

33. Ohkawa K, Hashiguchi M, Ohno K, Kiuchi C, Takahashi S, et al. (2002) Risk factors for antituberculous chemotherapy-induced hepatotoxicity in Japanese pediatric patients. Clin Pharmacol Ther 72: 220-226.

34. Papastavros T, Dolovich LR, Holbrook A, Whitehead L, Loeb M (2002) Adverse events associated with pyrazinamide and levofloxacin in the treatment of latent multidrug-resistant tuberculosis. CMAJ 167: 131-136.

35. Younossian AB, Rochat T, Ketterer JP, Wacker J, Janssens JP (2005) High hepatotoxicity of pyrazinamide and ethambutol for treatment of laten tuberculosis. Eur Respir J 26: 462-464.

36. Senaratne WV, Pinidiyapathirage MJ, Perera GA, Wickremasinghe AR (2006) Anti-tuberculosis drug inducd hepatitis - a Sri Lankan experience. Ceylon Med J 51: 9-14.

37. Tostmann A, van den Boogaard J, Semvua H, Kisonga R, Kibiki GS, et al (2010) Antituberculosis drug-induced hepatotoxicity is uncommon in Tanzanian hospitalized pulmonary TB patients. Trop Med Int Health 15: 268-272.

38. Lucien K, Clement A, Fon N, Weledji P, Ndikvu C (2010) The effects of antiretroviral treatment on liver function enzymes among HIV-infected out patients attending the Central Hospital of Yaoundé, Cameroon. AJCEM 11 174-178.

39. Marks DJ, Dheda K, Dawson R, Ainslie G, Miller RF (2009) Adverse events to antituberculosis therapy: influence of HIV and antiretroviral drugs. Int J STD AIDS 20: 339-345.

40. Kwara A, Flanigan TP, Carter EJ (2005) Highly active antiretroviral therapy (HAART) in adults with tuberculosis: current status. Int $\mathrm{J}$ Tuberc Lung Dis 9 : 248-257

41. Sanne I, Mommeja-Marin H, Hinkle J, Bartlett JA, Lederman MM, et al. (2005) Severe hepatotoxicity associated with nevirapine use in HIV-infected subjects. J Infect Dis 191: 825-829.

42. Rivero A, Mira JA, Pineda JA (2007) Liver toxicity induced by non-nucleoside reverse transcriptase inhibitors. J Antimicrob Chemother 59: 342-346. 